\title{
Employing Common Limit Range Property to Prove Unified Metrical Common Fixed Point Theorems
}

\author{
Mohammad Imdad ${ }^{1}$ and Sunny Chauhan ${ }^{2}$ \\ ${ }^{1}$ Department of Mathematics, Aligarh Muslim University, Aligarh 202 002, India \\ ${ }^{2}$ Near Nehru Training Centre, H. No. 274, Nai Basti B-14, Bijnor, Uttar Pradesh 246 701, India \\ Correspondence should be addressed to Sunny Chauhan; sun.gkv@gmail.com
}

Received 29 January 2013; Accepted 4 April 2013

Academic Editor: Chuanxi Qian

Copyright ( 2013 M. Imdad and S. Chauhan. This is an open access article distributed under the Creative Commons Attribution License, which permits unrestricted use, distribution, and reproduction in any medium, provided the original work is properly cited.

\begin{abstract}
The purpose of this paper is to emphasize the role of "common limit range property" to ascertain the existence of common fixed point in metric spaces satisfying an implicit function essentially due to the paper of Ali and Imdad (2008). As an application to our main result, we derive a fixed point theorem for four finite families of self-mappings which can be utilized to derive common fixed point theorems involving any finite number of mappings. Our results improve and extend a host of previously known results including the ones contained in the paper of Ali and Imdad (2008). We also furnish some illustrative examples to support our main results.
\end{abstract}

\section{Introduction and Preliminaries}

The well-known Banach fixed point theorem is often referred to as Banach contraction principle which appeared in its explicit form in the thesis of Banach in 1922 [1]. Owing to its simplicity and usefulness, it became a very popular and powerful tool in solving existence problems in pure and applied sciences which include biology, medicine, physics, and computer science (see $[2,3])$. This natural theorem asserts that every contraction mapping defined on a complete metric space has a unique fixed point and that fixed point can be explicitly obtained as limit of repeated iteration of the mapping at any point of the underlying space. Evidently, every contraction mapping is a continuous but not conversely.

A result on the existence and uniqueness of common fixed point in metric spaces generally involves conditions on commutativity, continuity, and contraction along with a suitable condition on the containment of range of one mapping into the range of other. Hence, one is always required to improve one or more of these conditions to prove a new fixed point theorem. In the recent past, several authors have contributed to the vigorous development of metric fixed point theory (e.g., [4-18]).
In metric fixed point theory, recently implicit relations are utilized to cover several contraction conditions in one go rather than proving a separate theorem for each contraction condition. The first ever attempt to coin an implicit relation can be traced back to Popa [19]. In 2008, Ali and Imdad [20] introduced a new class of implicit functions which covers several classes of contraction conditions such as Ćirić quasi-contractions, generalized contractions, $\psi$-type contractions, rational inequalities, and among others. They (i.e., Ali and Imdad [20]) proved some fixed point theorems for weakly compatible mappings satisfying common property (E.A). Thereafter, many researchers utilized various implicit relations to prove a number of fixed point theorems in different settings (e.g., [2127]).

In this paper, utilizing the implicit function of Ali and Imdad [20], we prove some common fixed point theorems for two pairs of weakly compatible mappings employing common limit range property. In process, many known results (especially the ones contained in Ali and Imdad [20]) are enriched and improved. Some related results are also derived besides furnishing illustrative examples. 
Definition 1. Let $A, S: X \rightarrow X$ be two self-mappings of a metric space $(X, d)$. Then the pair $(A, S)$ is said to be

(1) commuting if $A S x=S A x$, for all $x \in X$,

(2) weakly commuting (cf. [28]) if $d(A S x, S A x) \leq$ $d(A x, S x)$, for all $x \in X$,

(3) compatible (cf. [29]) if $\lim _{n \rightarrow \infty} d\left(A S x_{n}, S A x_{n}\right)=0$ for each sequence $\left\{x_{n}\right\}$ in $X$ such that $\lim _{n \rightarrow \infty} A x_{n}=$ $\lim _{n \rightarrow \infty} S x_{n}$,

(4) noncompatible (cf. [30]) if there exists a sequence $\left\{x_{n}\right\}$ in $X$ such that $\lim _{n \rightarrow \infty} A x_{n}=\lim _{n \rightarrow \infty} S x_{n}$ but $\lim _{n \rightarrow \infty} d\left(A S x_{n}, S A x_{n}\right)$ is either nonzero or nonexistent,

(5) weakly compatible (cf. [31]) if they commute at their coincidence points, that is, $A S u=S A u$ whenever $A u=S u$, for some $u \in X$.

For more details on systematic comparisons and illustrations of earlier described notions, we refer to Murthy [32].

Definition 2 (cf. [33]). A pair $(A, S)$ of self-mappings of a metric space $(X, d)$ is said to satisfy the property (E.A) if there exists a sequence $\left\{x_{n}\right\}$ in $X$ such that

$$
\lim _{n \rightarrow \infty} A x_{n}=\lim _{n \rightarrow \infty} S x_{n}=t
$$

for some $t \in X$.

Hence any pair of compatible as well as noncompatible self-mappings of a metric space $(X, d)$ satisfy the property (E.A) but a pair of mappings satisfying the property (E.A) need not be noncompatible (see [34, Example 1]).

In 2005, Liu et al. [35] defined the notion of common property (E.A) for hybrid pairs of mappings which contains the property (E.A).

Definition 3. Two pairs $(A, S)$ and $(B, T)$ of self-mappings of a metric space $(X, d)$ are said to satisfy the common property (E.A), if there exist two sequences $\left\{x_{n}\right\}$ and $\left\{y_{n}\right\}$ in $X$ such that

$$
\lim _{n \rightarrow \infty} A x_{n}=\lim _{n \rightarrow \infty} S x_{n}=\lim _{n \rightarrow \infty} B y_{n}=\lim _{n \rightarrow \infty} T y_{n}=t,
$$

for some $t \in X$.

Motivated by the observation that the majority of the fixed point results always require the closedness of the underlying subspaces for the existence of common fixed point under the property (E.A) and common property (E.A), Sintunavarat and Kumam [36] coined the idea of "common limit range property" (also see [37]). Recently, Imdad et al. [38] extended the notion of common limit range property to two pairs of self-mappings which relaxes the requirements on closedness of the underlying subspaces.

Definition 4 (cf. [36]). A pair $(A, S)$ of self-mappings of a metric space $(X, d)$ is said to satisfy the common limit range property with respect to $S$, denoted by $\left(\mathrm{CLR}_{S}\right)$, if there exists a sequence $\left\{x_{n}\right\}$ in $X$ such that

$$
\lim _{n \rightarrow \infty} A x_{n}=\lim _{n \rightarrow \infty} S x_{n}=t,
$$

where $t \in S(X)$.

Thus, one can infer that a pair $(A, S)$ satisfying the property (E.A) along with closedness of the subspace $S(X)$ always enjoys the $\left(\mathrm{CLR}_{S}\right)$ property with respect to the mapping $S$ (see [38, Examples 2.16-2.17]).

Definition 5. Two pairs $(A, S)$ and $(B, T)$ of self-mappings of a metric space $(X, d)$ are said to satisfy the common limit range property with respect to mappings $S$ and $T$, denoted by $\left(\mathrm{CLR}_{S T}\right)$, if there exist two sequences $\left\{x_{n}\right\}$ and $\left\{y_{n}\right\}$ in $X$ such that

$$
\lim _{n \rightarrow \infty} A x_{n}=\lim _{n \rightarrow \infty} S x_{n}=\lim _{n \rightarrow \infty} B y_{n}=\lim _{n \rightarrow \infty} T y_{n}=t,
$$

where $t \in S(X) \cap T(X)$

Definition 6 (cf. [39]). Two families of self-mappings $\left\{A_{i}\right\}_{i=1}^{m}$ and $\left\{S_{k}\right\}_{k=1}^{n}$ are said to be pairwise commuting if

(1) $A_{i} A_{j}=A_{j} A_{i}$ for all $i, j \in\{1,2, \ldots, m\}$,

(2) $S_{k} S_{l}=S_{l} S_{k}$ for all $k, l \in\{1,2, \ldots, n\}$,

(3) $A_{i} S_{k}=S_{k} A_{i}$ for all $i \in\{1,2, \ldots, m\}$ and $k \in$ $\{1,2, \ldots, n\}$.

\section{Implicit Functions}

In an attempt to cover Ćirić's quasi-contractions, Ali and Imdad [20] introduced a new class of implicit functions which includes a variety of contraction classes such as Ćirić quasi-contractions, generalized contractions, $\psi$-type contractions, rational inequalities, and among others.

Let $\Phi$ be the family of lower semicontinuous functions $\phi: \mathbb{R}^{6} \rightarrow \mathbb{R}$ satisfying the following conditions:

$$
\begin{aligned}
& \left(\phi_{1}\right): \phi(t, 0, t, 0,0, t)>0, \text { for all } t>0, \\
& \left(\phi_{2}\right): \phi(t, 0,0, t, t, 0)>0, \text { for all } t>0, \\
& \left(\phi_{3}\right): \phi(t, t, 0,0, t, t)>0, \text { for all } t>0 .
\end{aligned}
$$

The following examples furnished in Ali and Imdad's [20] establishes the utility of the preceeding definition.

Example 7. Define $\phi\left(t_{1}, t_{2}, t_{3}, t_{4}, t_{5}, t_{6}\right): \mathbb{R}^{6} \rightarrow \mathbb{R}$ as

$$
\begin{array}{r}
\phi\left(t_{1}, t_{2}, t_{3}, t_{4}, t_{5}, t_{6}\right)=t_{1}-k \max \left\{t_{2}, t_{3}, t_{4}, t_{5}, t_{6}\right\}, \\
\text { where } k \in[0,1) .
\end{array}
$$

Example 8. Define $\phi\left(t_{1}, t_{2}, t_{3}, t_{4}, t_{5}, t_{6}\right): \mathbb{R}^{6} \rightarrow \mathbb{R}$ as

$$
\phi\left(t_{1}, t_{2}, t_{3}, t_{4}, t_{5}, t_{6}\right)=t_{1}-k \max \left\{t_{2}, t_{3}, t_{3} t_{5}, t_{4} t_{6}\right\},
$$

where $k \in[0,1)$. 
Example 9. Define $\phi\left(t_{1}, t_{2}, t_{3}, t_{4}, t_{5}, t_{6}\right): \mathbb{R}^{6} \rightarrow \mathbb{R}$ as

$\phi\left(t_{1}, t_{2}, t_{3}, t_{4}, t_{5}, t_{6}\right)=t_{1}-k\left[\max \left\{t_{2}^{2}, t_{3} t_{4}, t_{5} t_{6}, t_{3} t_{5}, t_{4} t_{6}\right\}\right]^{1 / 2}$,

where $k \in[0,1)$.

Example 10. Define $\phi\left(t_{1}, t_{2}, t_{3}, t_{4}, t_{5}, t_{6}\right): \mathbb{R}^{6} \rightarrow \mathbb{R}$ as

$$
\begin{aligned}
& \phi\left(t_{1}, t_{2}, t_{3}, t_{4}, t_{5}, t_{6}\right) \\
&=t_{1}-\alpha\left[\beta \max \left\{t_{2}, t_{3}, t_{4}, t_{5}, t_{6}\right\}\right. \\
&\left.+(1-\beta)\left(\max \left\{t_{2}^{2}, t_{3} t_{4}, t_{5} t_{6}, t_{3} t_{6}, t_{4} t_{5}\right\}\right)^{1 / 2}\right],
\end{aligned}
$$

where $\alpha \in[0,1)$ and $\beta \geq 0$.

Example 11. Define $\phi\left(t_{1}, t_{2}, t_{3}, t_{4}, t_{5}, t_{6}\right): \mathbb{R}^{6} \rightarrow \mathbb{R}$ as

$$
\begin{aligned}
& \phi\left(t_{1}, t_{2}, t_{3}, t_{4}, t_{5}, t_{6}\right) \\
& =t_{1}^{2}-\alpha \max \left\{t_{2}^{2}, t_{3}^{2}, t_{4}^{2}\right\}-\beta \max \left\{t_{3} t_{5}, t_{4} t_{6}\right\}-\gamma t_{5} t_{6},
\end{aligned}
$$

where $\alpha, \beta, \gamma \geq 0$ and $\alpha+\gamma<1$.

Example 12. Define $\phi\left(t_{1}, t_{2}, t_{3}, t_{4}, t_{5}, t_{6}\right): \mathbb{R}^{6} \rightarrow \mathbb{R}$ as

$$
\begin{aligned}
\phi\left(t_{1}, t_{2}, t_{3}, t_{4}, t_{5}, t_{6}\right)= & \left(1+\alpha t_{2}\right) t_{1}-\alpha \max \left\{t_{3} t_{4}, t_{5} t_{6}\right\} \\
& -\beta \max \left\{t_{2}, t_{3}, t_{4}, t_{5}, t_{6}\right\},
\end{aligned}
$$

where $\alpha \geq 0$ and $\beta \in[0,1)$.

Example 13. Define $\phi\left(t_{1}, t_{2}, t_{3}, t_{4}, t_{5}, t_{6}\right): \mathbb{R}^{6} \rightarrow \mathbb{R}$ as

$$
\begin{aligned}
& \phi\left(t_{1}, t_{2}, t_{3}, t_{4}, t_{5}, t_{6}\right) \\
& =t_{1}-\alpha t_{2}-\beta \max \left\{t_{3}, t_{4}\right\}-\gamma \max \left\{t_{3}+t_{4}, t_{5}+t_{6}\right\},
\end{aligned}
$$

where $\alpha, \beta, \gamma \geq 0$ and $\alpha+\beta+2 \gamma<1$.

Example 14. Define $\phi\left(t_{1}, t_{2}, t_{3}, t_{4}, t_{5}, t_{6}\right): \mathbb{R}^{6} \rightarrow \mathbb{R}$ as

$$
\phi\left(t_{1}, t_{2}, t_{3}, t_{4}, t_{5}, t_{6}\right)=t_{1}-\psi\left(\max \left\{t_{2}, t_{3}, t_{4}, t_{5}, t_{6}\right\}\right),
$$

where $\psi: \mathbb{R} \rightarrow \mathbb{R}$ is an upper semicontinuous function such that $\psi(0)=0$ and $\psi(t)<t$ for all $t>0$.

Example 15. Define $\phi\left(t_{1}, t_{2}, t_{3}, t_{4}, t_{5}, t_{6}\right): \mathbb{R}^{6} \rightarrow \mathbb{R}$ as

$$
\phi\left(t_{1}, t_{2}, t_{3}, t_{4}, t_{5}, t_{6}\right)=t_{1}-\psi\left(t_{2}, t_{3}, t_{4}, t_{5}, t_{6}\right),
$$

where $\psi: \mathbb{R}^{5} \rightarrow \mathbb{R}$ is an upper semicontinuous function such that $\max \{\psi(0, t, 0,0, t), \psi(0,0, t, t, 0), \psi(t, 0,0, t, t)\}<t$ for each $t>0$.
Example 16. Define $\phi\left(t_{1}, t_{2}, t_{3}, t_{4}, t_{5}, t_{6}\right): \mathbb{R}^{6} \rightarrow \mathbb{R}$ as

$$
\phi\left(t_{1}, t_{2}, t_{3}, t_{4}, t_{5}, t_{6}\right)=t_{1}^{2}-\psi\left(t_{2}^{2}, t_{3} t_{4}, t_{5} t_{6}, t_{3} t_{6}, t_{4} t_{5}\right),
$$

where $\psi: \mathbb{R}^{5} \rightarrow \mathbb{R}$ is an upper semicontinuous function such that $\max \{\psi(0,0,0, t, 0), \psi(0,0,0,0, t), \psi(t, 0, t, 0,0)\}<t$ for each $t>0$.

Example 17. Define $\phi\left(t_{1}, t_{2}, t_{3}, t_{4}, t_{5}, t_{6}\right): \mathbb{R}^{6} \rightarrow \mathbb{R}$ as

$$
\begin{aligned}
& \phi\left(t_{1}, t_{2}, t_{3}, t_{4}, t_{5}, t_{6}\right) \\
& \quad= \begin{cases}t_{1}-\alpha t_{2}-\beta \frac{t_{3}^{2}+t_{4}^{2}}{t_{3}+t_{4}}-\gamma\left(t_{5}+t_{6}\right), & \text { if } t_{3}+t_{4} \neq 0 ; \\
t_{1}, & \text { if } t_{3}+t_{4}=0,\end{cases}
\end{aligned}
$$

where $\alpha, \beta, \gamma \geq 0$ and $\beta+\gamma<1$.

Example 18. Define $\phi\left(t_{1}, t_{2}, t_{3}, t_{4}, t_{5}, t_{6}\right): \mathbb{R}^{6} \rightarrow \mathbb{R}$ as

$$
\begin{gathered}
\phi\left(t_{1}, t_{2}, t_{3}, t_{4}, t_{5}, t_{6}\right) \\
= \begin{cases}t_{1}^{p}-k t_{2}^{p}-\frac{t_{3} t_{4}^{p}+t_{5} t_{6}^{p}}{t_{3}+t_{4}}, & \text { if } t_{3}+t_{4} \neq 0 ; \\
t_{1}, & \text { if } t_{3}+t_{4}=0,\end{cases}
\end{gathered}
$$

where $p \geq 1$ and $0 \leq k<\infty$.

Example 19. Define $\phi\left(t_{1}, t_{2}, t_{3}, t_{4}, t_{5}, t_{6}\right): \mathbb{R}^{6} \rightarrow \mathbb{R}$ as

$$
\begin{aligned}
& \phi\left(t_{1}, t_{2}, t_{3}, t_{4}, t_{5}, t_{6}\right) \\
& \quad= \begin{cases}t_{1}-\alpha t_{2}-\beta \frac{t_{5}^{2}+t_{6}^{2}}{t_{5}+t_{6}}-\gamma\left(t_{3}+t_{4}\right), & \text { if } t_{5}+t_{6} \neq 0 ; \\
t_{1}, & \text { if } t_{5}+t_{6}=0,\end{cases}
\end{aligned}
$$

where $\alpha, \beta, \gamma \geq 0$ and $\beta+\gamma<1$.

Example 20. Define $\phi\left(t_{1}, t_{2}, t_{3}, t_{4}, t_{5}, t_{6}\right): \mathbb{R}^{6} \rightarrow \mathbb{R}$ as

$$
\begin{gathered}
\phi\left(t_{1}, t_{2}, t_{3}, t_{4}, t_{5}, t_{6}\right) \\
= \begin{cases}t_{1}-k t_{2}-\frac{t_{3} t_{4}+t_{5} t_{6}}{t_{5}+t_{6}}, & \text { if } t_{5}+t_{6} \neq 0 ; \\
t_{1}, & \text { if } t_{5}+t_{6}=0,\end{cases}
\end{gathered}
$$

where $0 \leq k<\infty$.

Example 21. Define $\phi\left(t_{1}, t_{2}, t_{3}, t_{4}, t_{5}, t_{6}\right): \mathbb{R}^{6} \rightarrow \mathbb{R}$ as

$$
\begin{gathered}
\phi\left(t_{1}, t_{2}, t_{3}, t_{4}, t_{5}, t_{6}\right) \\
=\left\{\begin{aligned}
t_{1}-k t_{2}- & \frac{t_{3} t_{4}+t_{5} t_{6}}{t_{3}+t_{4}}-\frac{t_{3} t_{5}+t_{4} t_{6}}{t_{5}+t_{6}}, \\
& \text { if } t_{3}+t_{4} \neq 0, t_{5}+t_{6} \neq 0 ; \\
t_{1}, & \text { if } t_{3}+t_{4}=0, t_{5}+t_{6}=0,
\end{aligned}\right.
\end{gathered}
$$

where $0 \leq k<\infty$. 
Example 22. Define $\phi\left(t_{1}, t_{2}, t_{3}, t_{4}, t_{5}, t_{6}\right): \mathbb{R}^{6} \rightarrow \mathbb{R}$ as

$$
\phi\left(t_{1}, t_{2}, t_{3}, t_{4}, t_{5}, t_{6}\right)=t_{1}-\frac{t_{3} t_{4}+t_{5} t_{6}}{1+t_{2}}
$$

Example 23. Define $\phi\left(t_{1}, t_{2}, t_{3}, t_{4}, t_{5}, t_{6}\right): \mathbb{R}^{6} \rightarrow \mathbb{R}$ as

$$
\phi\left(t_{1}, t_{2}, t_{3}, t_{4}, t_{5}, t_{6}\right)=t_{1}-\alpha t_{2}-\beta \frac{t_{3}+t_{4}}{1+t_{5} t_{6}},
$$

where $\alpha, \beta \in[0,1)$.

Example 24. Define $\phi\left(t_{1}, t_{2}, t_{3}, t_{4}, t_{5}, t_{6}\right): \mathbb{R}^{6} \rightarrow \mathbb{R}$ as

$$
\phi\left(t_{1}, t_{2}, t_{3}, t_{4}, t_{5}, t_{6}\right)=t_{1}^{2}-\alpha t_{2}^{2}-\beta \frac{t_{5} t_{6}}{1+t_{3}^{2}+t_{4}^{2}},
$$

where $\alpha, \beta \geq 0$ and $\alpha+\beta<1$.

Example 25. Define $\phi\left(t_{1}, t_{2}, t_{3}, t_{4}, t_{5}, t_{6}\right): \mathbb{R}^{6} \rightarrow \mathbb{R}$ as

$$
\phi\left(t_{1}, t_{2}, t_{3}, t_{4}, t_{5}, t_{6}\right)=t_{1}^{3}-\frac{t_{3}^{2} t_{4}^{2}+t_{5}^{2} t_{6}^{2}}{1+t_{2}} .
$$

Example 26. Define $\phi\left(t_{1}, t_{2}, t_{3}, t_{4}, t_{5}, t_{6}\right): \mathbb{R}^{6} \rightarrow \mathbb{R}$ as

$$
\phi\left(t_{1}, t_{2}, t_{3}, t_{4}, t_{5}, t_{6}\right)=t_{1}^{3}-\alpha t_{1}^{2} t_{2}-\beta t_{1} t_{3} t_{4}-\gamma t_{5}^{2} t_{6}-\eta t_{5} t_{6}^{2},
$$

where $\alpha, \beta, \gamma, \eta \geq 0$ and $\alpha+\gamma+\eta<1$.

Apart from earlier stated definitions, still there are many contractive definitions which meet the requirements $\left(\phi_{1}\right)$, $\left(\phi_{2}\right)$ and $\left(\phi_{3}\right)$ but due to paucity of the space we have not opted to include more examples.

\section{Main Results}

Firstly, we observe the following.

Lemma 27. Let $A, B, S$, and $T$ be self-mappings of a metric space $(X, d)$. Suppose the following:

(1) the pair $(A, S)$ satisfies the $\left(C L R_{S}\right)$ property (or $(B, T)$ satisfies the $\left(C L R_{T}\right)$ property),

(2) $A(X) \subset T(X)($ or $B(X) \subset S(X))$,

(3) $T(X)($ or $S(X))$ is a closed subset of $X$,

(4) there exists $\phi \in \Phi$ such that (for all $x, y \in X$ )

$$
\begin{gathered}
\phi(d(A x, B y), d(S x, T y), d(A x, S x), d(B y, T y), \\
d(S x, B y), d(T y, A x)) \leq 0 .
\end{gathered}
$$

Then the pairs $(A, S)$ and $(B, T)$ share the $\left(C L R_{S T}\right)$ property.

Proof. If the pair $(A, S)$ enjoys the $\left(\mathrm{CLR}_{S}\right)$ property with respect to mapping $S$, then there exists a sequence $\left\{x_{n}\right\}$ in $X$ such that

$$
\lim _{n \rightarrow \infty} A x_{n}=\lim _{n \rightarrow \infty} S x_{n}=t
$$

where $t \in S(X)$. Since $A(X) \subset T(X)$, for each sequence $\left\{x_{n}\right\}$ there exists a sequence $\left\{y_{n}\right\}$ in $X$ such that $A x_{n}=T y_{n}$. Therefore, due to closedness of $T(X)$,

$$
\lim _{n \rightarrow \infty} T y_{n}=\lim _{n \rightarrow \infty} A x_{n}=t
$$

where $t \in S(X) \cap T(X)$. Thus in all, we have $A x_{n} \rightarrow t, S x_{n} \rightarrow$ $t$ and $T y_{n} \rightarrow t$ as $n \rightarrow \infty$. Now, we show that $B y_{n} \rightarrow t$ as $n \rightarrow \infty$. On using inequality (25) with $x=x_{n}, y=y_{n}$, we have

$$
\begin{aligned}
& \phi\left(d\left(A x_{n}, B y_{n}\right), d\left(S x_{n}, T y_{n}\right), d\left(A x_{n}, S x_{n}\right),\right. \\
& \left.\quad d\left(B y_{n}, T y_{n}\right), d\left(S x_{n}, B y_{n}\right), d\left(T y_{n}, A x_{n}\right)\right) \leq 0 .
\end{aligned}
$$

Let on contrary that $B y_{n} \rightarrow l(\neq t)$ as $n \rightarrow \infty$. Then, on taking limit as $n \rightarrow \infty$ in the preceeding inequality, we get

$$
\phi(d(t, l), d(t, t), d(t, t), d(l, t), d(t, l), d(t, t)) \leq 0,
$$

or

$$
\phi(d(t, l), 0,0, d(l, t), d(t, l), 0) \leq 0,
$$

which is a contradiction to $\left(\phi_{2}\right)$. Hence, $B y_{n} \rightarrow t$ which shows that the pairs $(A, S)$ and $(B, T)$ share the $\left(C_{L R}\right)$ property. This concludes the proof.

Remark 28. In general, the converse of Lemma 27 is not true (see [38, Example 3.5]).

Now, we state and prove our main result for two pairs of weakly compatible mappings satisfying the $\left(\mathrm{CLR}_{S T}\right)$ property.

Theorem 29. Let $A, B, S$, and $T$ be self-mappings of a metric space $(X, d)$ satisfying the inequality $(25)$ of Lemma 27 . If the pairs $(A, S)$ and $(B, T)$ share the $\left(C L R_{S T}\right)$ property, then $(A, S)$ and $(B, T)$ have a coincidence point each. Moreover, $A, B, S$ and $T$ have a unique common fixed point provided that both pairs $(A, S)$ and $(B, T)$ are weakly compatible.

Proof. Since the pairs $(A, S)$ and $(B, T)$ satisfy the $\left(\mathrm{CLR}_{S T}\right)$ property, there exist two sequences $\left\{x_{n}\right\}$ and $\left\{y_{n}\right\}$ in $X$ such that

$$
\lim _{n \rightarrow \infty} A x_{n}=\lim _{n \rightarrow \infty} S x_{n}=\lim _{n \rightarrow \infty} B y_{n}=\lim _{n \rightarrow \infty} T y_{n}=t,
$$

where $t \in S(X) \cap T(X)$. Since $t \in S(X)$, there exists a point $u \in X$ such that $S u=t$. We show that $A u=S u$. If not, then using inequality (25) with $x=u, y=y_{n}$, we get

$$
\begin{gathered}
\phi\left(d\left(A u, B y_{n}\right), d\left(S u, T y_{n}\right), d(A u, S u), d\left(B y_{n}, T y_{n}\right),\right. \\
\left.d\left(S u, B y_{n}\right), d\left(T y_{n}, A u\right)\right) \leq 0,
\end{gathered}
$$

which on making $n \rightarrow \infty$ reduces to

$$
\phi(d(A u, t), d(t, t), d(A u, t), d(t, t), d(t, t), d(t, A u)) \leq 0,
$$

or

$$
\phi(d(A u, t), 0, d(A u, t), 0,0, d(t, A u)) \leq 0,
$$


a contradiction to $\left(\phi_{1}\right)$. Hence, $A u=S u=t$. Therefore, $u$ is a coincidence point of the pair $(A, S)$.

Also $t \in T(X)$, there exists a point $v \in X$ such that $T v=t$. We assert that $B v=T v$. If not, then using inequality (25) with $x=u, y=v$, we get

$$
\begin{gathered}
\phi(d(A u, B v), d(S u, T v), d(A u, S u), d(B v, T v), \\
d(S u, B v), d(T v, A u)) \leq 0,
\end{gathered}
$$

which reduces to

$$
\phi(d(t, B v), d(t, t), d(t, t), d(B v, t), d(t, B v), d(t, t)) \leq 0,
$$

or

$$
\phi(d(t, B v), 0,0, d(B v, t), d(t, B v), 0) \leq 0,
$$

a contradiction to $\left(\phi_{2}\right)$. Hence, $B v=T v=t$, which shows that $v$ is a coincidence point of the pair $(B, T)$.

Since the pair $(A, S)$ is weakly compatible and $A u=S u$, hence $A t=A S u=S A u=S t$. Now, we show that $t$ is a common fixed point of the pair $(A, S)$. Suppose that $A t \neq t$, using inequality (25) with $x=t, y=v$, we have

$$
\begin{gathered}
\phi(d(A t, B v), d(S t, T v), d(A t, S t), d(B v, T v), \\
d(S t, B v), d(T v, A t)) \leq 0,
\end{gathered}
$$

or

$$
\phi(d(A t, t), d(A t, t), 0,0, d(A t, t), d(t, A t)) \leq 0,
$$

a contradiction to $\left(\phi_{3}\right)$; we get $A t=t=S t$ which shows that $t$ is a common fixed point of the pair $(A, S)$.

Also the pair $(B, T)$ is weakly compatible and $B v=T v$, then $B t=B T v=T B v=T t$. Suppose that $B t \neq t$, then using inequality (25) with $x=u, y=t$, we have

$$
\begin{gathered}
\phi(d(A u, B t), d(S u, T t), d(A u, S u), d(B t, T t), \\
d(S u, B t), d(T t, A u)) \leq 0
\end{gathered}
$$

or

$$
\phi(d(t, B t), d(t, B t), 0,0, d(t, B t), d(B t, t)) \leq 0
$$

a contradiction to $\left(\phi_{3}\right)$. Therefore, $B t=t=T t$ which shows that $t$ is a common fixed point of the pair $(B, T)$ and in all $t$ is a common fixed point of both pairs $(A, S)$ and $(B, T)$. Uniqueness of common fixed point is an easy consequence of the inequality (25) in view of condition $\left(\phi_{3}\right)$. This concludes the proof.

Remark 30. Theorem 29 improves the corresponding results contained in Ali and Imdad's [20, Theorem 3.1] as closedness of the underlying subspaces is not required.

Now, we present an example which demonstrates the validity of the hypotheses and degree of generality of our main result over comparable ones from the existing literature.
Example 31. Consider $X=[5,21)$ equipped with the usual metric. Define four self-mappings $A, B, S$, and $T$ by

$$
\begin{aligned}
& A(x)= \begin{cases}5, & \text { if } x \in\{5\} \cup(9,21) ; \\
20, & \text { if } x \in(5,9]\end{cases} \\
& B(x)= \begin{cases}5, & \text { if } x \in\{5\} \cup(9,21) ; \\
13, & \text { if } x \in(5,9]\end{cases} \\
& S(x)= \begin{cases}5, & \text { if } x=5 ; \\
\frac{x+1}{2}, & \text { if } x \in(5,9] ;\end{cases} \\
& T(x)= \begin{cases}5, & \text { if } x \in(9,21), \\
18, & \text { if } x \in(5,9] \\
x-4, & \text { if } x \in(9,21)\end{cases}
\end{aligned}
$$

Also, define implicit function $\phi\left(t_{1}, t_{2}, t_{3}, t_{4}, t_{5}, t_{6}\right)$ : $\left(\mathbb{R}^{+}\right)^{6} \rightarrow \mathbb{R}$ as

$$
\phi\left(t_{1}, t_{2}, t_{3}, t_{4}, t_{5}, t_{6}\right)=t_{1}-k \max \left\{t_{2}, t_{3}, t_{4}, t_{5}, t_{6}\right\}
$$

or

$$
\begin{gathered}
d(A x, B y) \\
\leq k \max \{d(S x, T y), d(A x, S x), d(B y, T y), \\
d(S x, B y), d(T y, A x)\},
\end{gathered}
$$

for all $x, y \in X$ and $k \in[0,1)$. By a routine calculation, one can verify the inequality (44) with $k=1 / 2$. If we choose two sequences as $\left\{x_{n}\right\}=\{9+(1 / n)\}_{n \in \mathbb{N}},\left\{y_{n}\right\}=\{5\}$ (or $\left\{x_{n}\right\}=\{5\}$, $\left.\left\{y_{n}\right\}=\{9+(1 / n)\}_{n \in \mathbb{N}}\right)$, then the pairs $(A, S)$ and $(B, T)$ satisfy the $\left(\mathrm{CLR}_{S T}\right)$ property:

$$
\begin{aligned}
\lim _{n \rightarrow \infty} A x_{n} & =\lim _{n \rightarrow \infty} S x_{n}=\lim _{n \rightarrow \infty} B y_{n} \\
& =\lim _{n \rightarrow \infty} T y_{n}=5 \in S(X) \cap T(X) .
\end{aligned}
$$

Also, $A(X)=\{5,20\} \nsubseteq[5,17) \cup\{18\}=T(X)$ and $B(X)=\{5,13\} \nsubseteq[5,11)=S(X)$. Thus all the conditions of Theorem 29 are satisfied and 5 is a unique common fixed point of the pairs $(A, S)$ and $(B, T)$ which also remains a point of coincidence as well. Here, one may notice that all the involved mappings are discontinuous at their unique common fixed point 5.

Notice that the subspaces $S(X)$ and $T(X)$ are not closed subspaces of $X$; therefore, Theorem 29 of Ali and Imdad [20] cannot be used in the context of this example which establishes the genuineness of our extension.

Theorem 32. Let $A, B, S$, and $T$ be self-mappings of a metric space $(X, d)$ satisfying all the hypotheses of Lemma 27 . Then $A, B, S$, and $T$ have a unique common fixed point provided that both pairs $(A, S)$ and $(B, T)$ are weakly compatible.

Proof. In view of Lemma 27, the pairs $(A, S)$ and $(B, T)$ share the $\left(\mathrm{CLR}_{S T}\right)$ property so that there exist two sequences $\left\{x_{n}\right\}$ and $\left\{y_{n}\right\}$ in $X$ such that

$$
\lim _{n \rightarrow \infty} A x_{n}=\lim _{n \rightarrow \infty} S x_{n}=\lim _{n \rightarrow \infty} T y_{n}=\lim _{n \rightarrow \infty} B y_{n}=t,
$$


where $t \in S(X) \cap T(X)$. The rest of the proof can be completed on the lines of the proof of Theorem 29. This completes the proof.

The following example demonstrates the utility of Theorem 32 over Theorem 29.

Example 33. In the setting of Example 31, replace the selfmappings $A$ and $B$ by the following besides retaining the rest (i.e., $S$ and $T$ ):

$$
\begin{aligned}
& A(x)= \begin{cases}5, & \text { if } x \in\{5\} \cup(9,21) ; \\
15, & \text { if } x \in(5,9],\end{cases} \\
& B(x)= \begin{cases}5, & \text { if } x \in\{5\} \cup(9,21) ; \\
10, & \text { if } x \in(5,9],\end{cases} \\
& S(x)= \begin{cases}5, & \text { if } x=5 ; \\
11, & \text { if } x \in(5,9] ; \\
\frac{x+1}{2}, & \text { if } x \in(9,21),\end{cases} \\
& T(x)= \begin{cases}5, & \text { if } x=5 ; \\
17, & \text { if } x \in(5,9] ; \\
x-4, & \text { if } x \in(9,21) .\end{cases}
\end{aligned}
$$

Then, like earlier example, the pairs $(A, S)$ and $(B, T)$ satisfy the $\left(\mathrm{CLR}_{S T}\right)$ property. Consider the implicit function $\phi\left(t_{1}, t_{2}, t_{3}, t_{4}, t_{5}, t_{6}\right):\left(\mathbb{R}^{+}\right)^{6} \rightarrow \mathbb{R}$ as

$$
\phi\left(t_{1}, t_{2}, t_{3}, t_{4}, t_{5}, t_{6}\right)=t_{1}-k \max \left\{t_{2}, t_{3}, t_{4}, t_{5}, t_{6}\right\},
$$

which implies

$$
\begin{gathered}
d(A x, B y) \leq k \max \{d(S x, T y), d(A x, S x), d(B y, T y), \\
d(S x, B y), d(T y, A x)\},
\end{gathered}
$$

for all $x, y \in X$ and $k \in[0,1)$. By a routine calculation, one can verify inequality (49) with $k=1 / 2$. Also, $A(X)=$ $\{5,15\} \subset[5,17]=T(X)$ and $B(X)=\{5,10\} \subset[5,11]=S(X)$. The pairs $(A, S)$ and $(B, T)$ commute at 5 which is also their common coincidence point as well. Thus all the conditions of Theorems 32 are satisfied and 5 is a unique common fixed point of the involved mappings $A, B, S$, and $T$.

Here, it can be pointed out that Theorem 29 is not applicable to this example as both $S(X)$ and $T(X)$ are closed subsets of $X$ which demonstrates the situational utility of Theorem 32 over Theorem 29.

Corollary 34. The conclusions of Lemma 27, Theorems 29, and 32 remain true if inequality (25) is replaced by one of the following contraction conditions. For all $x, y \in X$,

$$
\begin{gathered}
d(A x, B y) \leq k \max \{d(S x, T y), d(A x, S x), d(B y, T y), \\
d(S x, B y), d(T y, A x)\},
\end{gathered}
$$

where $k \in[0,1)$.

\section{Consider}

$d(A x, B y)$

$\leq k \max \{d(S x, T y), d(A x, S x), d(A x, S x) d(S x, B y)$,

$$
d(B y, T y) d(T y, A x)\},
$$

where $k \in[0,1)$.

Consider

$d(A x, B y)$

$$
\begin{aligned}
\leq k[\max & \left\{d^{2}(S x, T y), d(A x, S x) d(B y, T y),\right. \\
& d(S x, B y) d(T y, A x), d(A x, S x) d(S x, B y), \\
& d(B y, T y) d(T y, A x)\}]^{1 / 2},
\end{aligned}
$$

where $k \in[0,1)$.

Consider

$$
\begin{gathered}
d(A x, B y) \\
\leq \alpha[\beta \max \{d(S x, T y), d(A x, S x), d(B y, T y), \\
d(S x, B y), d(T y, A x)\} \\
+(1-\beta)\left(\operatorname { m a x } \left\{d^{2}(S x, T y), d(A x, S x) d(B y, T y),\right.\right. \\
d(S x, B y) d(T y, A x), \\
d(A x, S x) d(T y, A x), \\
\left.d(B y, T y) d(S x, B y)\})^{1 / 2}\right],
\end{gathered}
$$

where $\alpha \in[0,1)$ and $\beta \geq 0$.

Consider

$d^{2}(A x, B y)$

$$
\begin{aligned}
\leq & \alpha \max \left\{d^{2}(S x, T y), d^{2}(A x, S x), d^{2}(B y, T y)\right\} \\
& +\beta \max \{d(A x, S x) d(S x, B y), d(B y, T y) d(T y, A x)\} \\
& +\gamma d(S x, B y) d(T y, A x),
\end{aligned}
$$

where $\alpha, \beta, \gamma \geq 0$ and $\alpha+\gamma<1$.

$$
\text { Consider }
$$

$$
\begin{aligned}
(1+\alpha d(S x, T y)) d(A x, B y) \\
\leq \alpha \max \{d(A x, S x) d(B y, T y), d(S x, B y) d(T y, A x)\} \\
+\beta \max \{d(S x, T y), d(A x, S x), d(B y, T y), \\
d(S x, B y), d(T y, A x)\},
\end{aligned}
$$

where $\alpha \geq 0$ and $\beta \in[0,1)$. 
Consider

$d(A x, B y)$

$$
\begin{gathered}
\leq \alpha d(S x, T y)+\beta \max \{d(A x, S x), d(B y, T y)\} \\
+\gamma \max \{d(A x, S x)+d(B y, T y), \\
d(S x, B y)+d(T y, A x)\},
\end{gathered}
$$

where $\alpha, \beta, \gamma \geq 0$ and $\alpha+\beta+2 \gamma<1$.

Consider

$d(A x, B y)$

$$
\begin{gathered}
\leq \psi(\max \{d(S x, T y), d(A x, S x), d(B y, T y), \\
d(S x, B y), d(T y, A x)\}),
\end{gathered}
$$

where $\psi: \mathbb{R}^{+} \rightarrow \mathbb{R}$ is an upper semicontinuous function such that $\psi(0)=0$ and $\psi(t)<t$ for all $t>0$.

Consider

$d(A x, B y) \leq \psi(d(S x, T y), d(A x, S x), d(B y, T y)$,

$$
d(S x, B y), d(T y, A x))
$$

where $\psi:\left(\mathbb{R}^{+}\right)^{5} \rightarrow \mathbb{R}$ is an upper semicontinuous function such that $\max \{\psi(0, t, 0,0, t), \psi(0,0, t, t, 0), \psi(t, 0,0, t, t)\}<t$ for each $t>0$.

Consider

$$
\begin{aligned}
& d^{2}(A x, B y) \\
& \leq \psi\left(d^{2}(S x, T y), d(A x, S x) d(B y, T y)\right. \\
& \quad d(S x, B y) d(T y, A x), \\
& \quad d(A x, S x) d(T y, A x), d(B y, T y) d(S x, B y)),
\end{aligned}
$$

where $\psi:\left(\mathbb{R}^{+}\right)^{5} \rightarrow \mathbb{R}$ is an upper semicontinuous function such that $\max \{\psi(0,0,0, t, 0), \psi(0,0,0,0, t), \psi(t, 0, t, 0,0)\}<t$ for each $t>0$.

In the following contraction conditions, one denotes $D=$ $d(A x, S x)+d(B y, T y)$ and $D_{1}=d(S x, B y)+d(T y, A x):$

$$
\begin{aligned}
& d(A x, B y) \\
& \leq \begin{cases}\alpha d(S x, T y)+\beta \frac{d^{2}(A x, S x)+d^{2}(B y, T y)}{d(A x, S x)+d(B y, T y)} & \text { if } D \neq 0 ; \\
+\gamma(d(S x, B y)+d(T y, A x)), & \text { if } D=0, \\
0, & \end{cases}
\end{aligned}
$$

where $\alpha, \beta, \gamma \geq 0$ and $\beta+\gamma<1$,

$$
d^{p}(A x, B y)
$$$$
\leq \begin{cases}k d^{p}(S x, T y) & \\ +\frac{d(A x, S x) d^{p}(B y, T y)+d(S x, B y) d^{p}(T y, A x)}{d(A x, S x)+d(B y, T y)} & \text { if } D \neq 0 \\ 0, & \text { if } D=0,\end{cases}
$$

$$
\begin{aligned}
& \text { where } \alpha, \beta, \gamma \geq 0 \text { and } \beta+\gamma<1, \\
& \qquad \begin{cases}k d(S x, T y) & \text { if } D_{1} \neq 0 \\
+\frac{d(A x, S x) d(B y, T y)+d(S x, B y) d(T y, A x)}{d(S x, B y)+d(T y, A x)} & \text { if } D_{1}=0, \\
0, & \end{cases}
\end{aligned}
$$

where $0 \leq k<\infty$,

$$
\begin{aligned}
& d(A x, B y) \\
& \leq\left\{\begin{array}{l}
k d(S x, T y) \\
+\frac{d(A x, S x) d(B y, T y)+d(S x, B y) d(T y, A x)}{d(A x, S x)+d(B y, T y)} \\
+\frac{d(A x, S x) d(S x, B y)+d(B y, T y) d(T y, A x)}{d(S x, B y)+d(T y, A x)} \\
0, \quad \text { if } D \neq 0, D_{1} \neq 0 \\
\text { if } D=0, D_{1}=0,
\end{array}\right.
\end{aligned}
$$

where $0 \leq k<\infty$

$$
\begin{gathered}
d(A x, B y) \leq \frac{d(A x, S x) d(B y, T y)+d(S x, B y) d(T y, A x)}{1+d(S x, T y)}, \\
d(A x, B y) \leq \alpha d(S x, T y)+\beta \frac{d(A x, S x)+d(B y, T y)}{1+d(S x, B y) d(T y, A x)},
\end{gathered}
$$

where $\alpha, \beta \in[0,1)$,

$$
\begin{aligned}
& d^{2}(A x, B y) \\
& \quad \leq \alpha d^{2}(S x, T y)+\beta \frac{d(S x, B y) d(T y, A x)}{1+d^{2}(A x, S x)+d^{2}(B y, T y)},
\end{aligned}
$$


where $\alpha, \beta \geq 0$ and $\alpha+\beta<1$,

$$
\begin{aligned}
& d^{3}(A x, B y) \\
& \leq \frac{d^{2}(A x, S x) d^{2}(B y, T y)+d^{2}(S x, B y) d^{2}(T y, A x)}{1+d(S x, T y)}, \\
& d^{3}(A x, B y) \\
& \leq \alpha d^{2}(A x, B y) d(S x, T y) \\
& \quad+\beta d(A x, B y) d(A x, S x) d(B y, T y) \\
& \quad+\gamma d^{2}(S x, B y) d(T y, A x)+\eta d(S x, B y) d^{2}(T y, A x),
\end{aligned}
$$

where $\alpha, \gamma, \eta, \beta \geq 0$ and $\alpha+\gamma+\eta<1$.

Proof. The proof of each inequality (50)-(67) easily follows from Theorem 29 in view of Examples 7-26.

Remark 35. Corollary 34 improves and generalizes a multitude of well-known results especially those contained in $[12,14,29,30,35,40-42]$.

By choosing $A, B, S$, and $T$ suitably, we can deduce corollaries involving two as well as three self-mappings. For the sake of naturality, we only derive the following corollary involving a pair of self-mappings.

Corollary 36. Let $A$ and $S$ be self-mappings of a metric space $(X, d)$. Suppose the following:

(1) the pair $(A, S)$ satisfies the $\left(C L R_{S}\right)$ property,

(2) there exists $\phi \in \Phi$ such that

$$
\begin{aligned}
& \phi(d(A x, A y), d(S x, S y), d(A x, S x), d(A y, S y), \\
& \quad d(S x, A y), d(S y, A x)) \leq 0, \\
& \quad \text { for all } x, y \in X .
\end{aligned}
$$

Then $(A, S)$ has a coincidence point. Moreover, if the pair $(A, S)$ is weakly compatible, then the pair has a unique common fixed point in $X$.

As an application of Theorem 29, we have the following result involving four finite families of self-mappings.

Theorem 37. Let $\left\{A_{i}\right\}_{i=1}^{m},\left\{B_{j}\right\}_{r=1}^{n},\left\{S_{k}\right\}_{k=1}^{p}$, and $\left\{T_{l}\right\}_{l=1}^{q}$ be four finite families of self-mappings of a metric space $(X, d)$ with $A=A_{1} A_{2} \cdots A_{m}, B=B_{1} B_{2} \cdots B_{n}, S=S_{1} S_{2} \cdots S_{p}$ and $T=T_{1} T_{2} \cdots T_{q}$ satisfying the condition (25). Suppose that the pairs $(A, S)$ and $(B, T)$ enjoy the $\left(C L R_{S T}\right)$ property, then $(A, S)$ and $(B, T)$ have a point of coincidence each.

Moreover, $\left\{A_{i}\right\}_{i=1}^{m},\left\{B_{j}\right\}_{j=1}^{n},\left\{S_{k}\right\}_{k=1}^{p}$, and $\left\{T_{l}\right\}_{l=1}^{q}$ have a unique common fixed point if the families $\left(\left\{A_{i}\right\},\left\{S_{k}\right\}\right)$ and $\left(\left\{B_{r}\right\},\left\{T_{h}\right\}\right)$ commute pairwise wherein $i \in\{1,2, \ldots, m\}, k \in$ $\{1,2, \ldots, p\}, j \in\{1,2, \ldots, n\}$, and $l \in\{1,2, \ldots, q\}$.

Proof. The proof of this theorem can be completed on the lines of Theorem 2.2 of Imdad et al. [10, Theorem 2.2].
Remark 38. (1) A result similar to Theorem 37 can be outlined in respect of Theorem 29.

(2) Theorem 37 improves and extends the result of Ćirić et al. [5] and Pathak et al. [25].

Now, we indicate that Theorem 37 can be utilized to derive common fixed point theorems for any finite number of mappings. As a sample, for five mappings, we can derive the following by setting one family of two members while the remaining three of single members.

Corollary 39. Let $A, B, R, S$, and $T$ be self-mappings of a metric space $(X, d)$. Suppose the following:

(1) the pairs $(A, S R)$ and $(B, T)$ share the $\left(C L R_{(S R)(T)}\right)$ property,

(2) there exists $\phi \in \Phi$ such that

$$
\begin{aligned}
& \phi(d(A x, B y), d(S R x, T y), d(A x, S R x), d(B y, T y), \\
& d(S R x, B y), d(T y, A x)) \leq 0, \\
& \quad \text { for all } x, y \in X .
\end{aligned}
$$

Then $(A, S R)$ and $(B, T)$ have a coincidence point each. Moreover, $A, B, R, S$, and $T$ have a unique common fixed point provided that both pairs $(A, S R)$ and $(B, T)$ commute pairwise, that is, $A S=S A, A R=R A, S R=R S, B T=T B$.

Similarly, we can derive a common fixed point theorem for six mappings by setting two families of two members while the rest two of single members.

Corollary 40. Let $A, B, H, R, S$, and $T$ be self-mappings of a metric space $(X, d)$. Suppose that

(1) the pairs $(A, S R)$ and $(B, T H)$ share the $\left(C L R_{(S R)(T H)}\right)$ property,

(2) there exists $\phi \in \Phi$ such that

$$
\begin{gathered}
\phi(d(A x, B y), d(S R x, T H y), d(A x, S R x), d(B y, T H y), \\
d(S R x, B y), d(T H y, A x)) \leq 0,
\end{gathered}
$$

for all $x, y \in X$.

Then $(A, S R)$ and $(B, T H)$ have a coincidence point each. Moreover, $A, B, H, R, S$, and $T$ have a unique common fixed point provided that both pairs $(A, S R)$ and $(B, T H)$ commute pairwise, that is, $A S=S A, A R=R A, S R=R S, B T=T B$, $B H=H B$, and $T H=H T$.

By setting $A_{1}=A_{2}=\cdots=A_{m}=A, B_{1}=B_{2}=\cdots=$ $B_{n}=B, S_{1}=S_{2}=\cdots=S_{p}=S$ and $T_{1}=T_{2}=\cdots=T_{q}=T$ in Theorem 37, we deduce the following.

Corollary 41. Let $A, B, S$, and $T$ be self-mappings of a metric space $(X, d)$. Suppose the following:

(1) the pairs $\left(A^{m}, S^{p}\right)$ and $\left(B^{n}, T^{q}\right)$ share the $\left(C L R_{S^{p}, T^{q}}\right)$ property, 
(2) there exists $\phi \in \Phi$ such that

$$
\begin{aligned}
& \phi\left(d\left(A^{m} x, B^{n} y\right), d\left(S^{p} x, T^{q} y\right), d\left(A^{m} x, S^{p} x\right),\right. \\
& \left.d\left(B^{n} y, T^{q} y\right), d\left(S^{p} x, B^{n} y\right), d\left(T^{q} y, A^{m} x\right)\right) \leq 0, \\
& \quad \text { for all } x, y \in X \text { where } m, n, p, q \text { are fixed positive } \\
& \quad \text { integers. }
\end{aligned}
$$

Then $A, B, S$, and $T$ have a unique common fixed point provided that $A S=S A$ and $B T=T B$.

Remark 42. Corollary 41 is a slight but partial generalization of Theorem 29 as the commutativity requirements (i.e., $A S=$ $S A$ and $B T=T B$ ) in this corollary are relatively stronger as compared to weak compatibility in Theorem 29.

Remark 43. Results similar to Corollary 41 can be derived from Theorem 29 and Corollary 34.

Remark 44. It may be noticed that the earlier proved results, namely, Theorems 29-37 (also Corollaries 36-41) remain valid in symmetric space $(X, d)$ whenever $d$ is continuous.

\section{Acknowledgment}

The authors wish to dedicate this work to Professor Mohammad Saeed Khan for his crucial role in their initial development in general and his fruitful observations on the first draft of this paper in particular.

\section{References}

[1] S. Banach, "Sur les operations dans les ensembles abstraits et leur application aux equations integrales," Fundamenta Mathematicae, vol. 3, pp. 133-181, 1922.

[2] W. A. Kirk, "Some recent results in metric fixed point theory," Journal of Fixed Point Theory and Applications, vol. 2, no. 2, pp. 195-207, 2007.

[3] C. Semple and M. Steel, Phylogenetics, vol. 24 of Oxford Lecture Series in Mathematics and its Applications, Oxford University Press, Oxford, UK, 2003.

[4] L. B. Ćirić, "Generalized contractions and fixed-point theorems," Publications de l'Institut Mathématique, vol. 12, no. 26, pp. 19-26, 1971.

[5] L. Ćirić, A. Razani, S. Radenović, and J. S. Ume, "Common fixed point theorems for families of weakly compatible maps," Computers \& Mathematics with Applications, vol. 55, no. 11, pp. 2533-2543, 2008.

[6] M. Imdad and J. Ali, "Jungck's common fixed point theorem and E.A property," Acta Mathematica Sinica, vol. 24, no. 1, pp. 87-94, 2008.

[7] M. Imdad, S. Chauhan, and Z. Kadelburg, "Fixed point theorems for mappings with common limit range property satisfying generalized $(\psi, \phi)$-weak contractive conditions," Mathematical Sciences, vol. 7, article 16, 2013.

[8] M. Imdad and Q. H. Khan, "Six mappings satisfying a rational inequality," Radovi Matematički, vol. 9, no. 2, pp. 251-260, 1999.

[9] M. Imdad, M. S. Khan, and S. Sessa, "On some weak conditions of commutativity in common fixed point theorems," International Journal of Mathematics and Mathematical Sciences, vol. 11, no. 2, pp. 289-296, 1988.
[10] M. Imdad, S. Kumar, and M. S. Khan, "Remarks on some fixed point theorems satisfying implicit relations," Radovi Matematički, vol. 11, no. 1, pp. 135-143, 2002.

[11] G. Jungck, "Commuting mappings and fixed points," The American Mathematical Monthly, vol. 83, no. 4, pp. 261-263, 1976.

[12] M. S. Khan and M. Imdad, "A common fixed point theorem for a class of mappings," Indian Journal of Pure and Applied Mathematics, vol. 14, no. 10, pp. 1220-1227, 1983.

[13] R. P. Pant, "Discontinuity and fixed points," Journal of Mathematical Analysis and Applications, vol. 240, no. 1, pp. 280-283, 1999.

[14] B. E. Rhoades, "A comparison of various definitions of contractive mappings," Transactions of the American Mathematical Society, vol. 226, pp. 257-290, 1977.

[15] B. E. Rhoades, "Some theorems on weakly contractive maps," in Proceedings of the 3rd World Congress of Nonlinear Analysts, vol. 47, pp. 2683-2693, 2001.

[16] S. Sessa and Y. J. Cho, "Compatible mappings and a common fixed point theorem of Chang type," Publicationes Mathematicae Debrecen, vol. 43, no. 3-4, pp. 289-296, 1993.

[17] S. Sessa, M. S. Khan, and M. Imdad, "A common fixed point theorem with a weak commutativity condition," Glasnik Matematicki Series III , vol. 21, no. 1, pp. 225-235, 1986.

[18] W. Shatanawi, "Fixed point theorems for nonlinear weakly $C$-contractive mappings in metric spaces," Mathematical and Computer Modelling, vol. 54, no. 11-12, pp. 2816-2826, 2011.

[19] V. Popa, "Some fixed point theorems for weakly compatible mappings," Radovi Matematički, vol. 10, no. 2, pp. 245-252, 2001.

[20] J. Ali and M. Imdad, "An implicit function implies several contraction conditions," Sarajevo Journal of Mathematics, vol. 4, no. 2, pp. 269-285, 2008.

[21] S. Chauhan and S. Kumar, "Coincidence and ffxed points in fuzzy metric spaces using common property (E.A)," Kochi Journal of Mathematics, vol. 8, pp. 135-154, 2013.

[22] D. Gopal, M. Imdad, and C. Vetro, "Impact of common property (E.A.) on fixed point theorems in fuzzy metric spaces," Fixed Point Theory and Applications, vol. 2011, Article ID 297360, 14 pages, 2011.

[23] M. Imdad, J. Ali, and M. Hasan, "Common fixed point theorems in modified intuitionistic fuzzy metric spaces," Iranian Journal of Fuzzy Systems, vol. 9, no. 5, pp. 77-92, 2012.

[24] M. Imdad, M. Tanveer, and M. Hasan, "Some common fixed point theorems in Menger PM spaces," Fixed Point Theory and Applications, vol. 2010, Article ID 819269, 14 pages, 2010.

[25] H. K. Pathak, R. Rodríguez-López, and R. K. Verma, "A common fixed point theorem using implicit relation and property (E.A) in metric spaces," Filomat, vol. 21, no. 2, pp. 211-234, 2007.

[26] V. Popa, M. Imdad, and J. Ali, "Using implicit relations to prove unified fixed point theorems in metric and 2-metric spaces," Bulletin of the Malaysian Mathematical Sciences Society B, vol. 33, no. 1, pp. 105-120, 2010.

[27] V. Popa, M. Imdad, and J. Ali, "Fixed point theorems for a class of mappings governed by strictly contractive implicit function," Southeast Asian Bulletin of Mathematics, vol. 34, no. 5, pp. 941952, 2010.

[28] S. Sessa, "On a weak commutativity condition of mappings in fixed point considerations," Publications de l'Institut Mathématique, vol. 32, no. 46, pp. 149-153, 1982.

[29] G. Jungck, "Compatible mappings and common fixed points," International Journal of Mathematics and Mathematical Sciences, vol. 9, no. 4, pp. 771-779, 1986. 
[30] R. P. Pant, "Noncompatible mappings and common fixed points," Soochow Journal of Mathematics, vol. 26, no. 1, pp. 29$35,2000$.

[31] G. Jungck and B. E. Rhoades, "Fixed points for set valued functions without continuity," Indian Journal of Pure and Applied Mathematics, vol. 29, no. 3, pp. 227-238, 1998.

[32] P. P. Murthy, "Important tools and possible applications of metric fixed point theory," Nonlinear Analysis: Theory, Methods \& Applications, vol. 47, no. 5, pp. 3479-3490, 2001.

[33] M. Aamri and D. El Moutawakil, "Some new common fixed point theorems under strict contractive conditions," Journal of Mathematical Analysis and Applications, vol. 270, no. 1, pp. 181188, 2002.

[34] J.-x. Fang and Y. Gao, "Common fixed point theorems under strict contractive conditions in Menger spaces," Nonlinear Analysis: Theory, Methods \& Applications, vol. 70, no. 1, pp. 184193, 2009.

[35] Y. Liu, J. Wu, and Z. Li, "Common fixed points of single-valued and multivalued maps," International Journal of Mathematics and Mathematical Sciences, no. 19, pp. 3045-3055, 2005.

[36] W. Sintunavarat and P. Kumam, "Common fixed point theorems for a pair of weakly compatible mappings in fuzzy metric spaces," Journal of Applied Mathematics, vol. 2011, Article ID 637958, 14 pages, 2011.

[37] S. L. Singh, B. D. Pant, and S. Chauhan, "Fixed point theorems in non-Archimedean Menger PM-spaces," Journal of Nonlinear Analysis and Optimization, vol. 3, no. 2, pp. 153-160, 2012.

[38] M. Imdad, B. D. Pant, and S. Chauhan, "Fixed point theorems in Menger spaces using the $\left(C L R_{S T}\right)$ property and applications," Journal of Nonlinear Analysis and Optimization, vol. 3, no. 2, pp. 225-237, 2012.

[39] M. Imdad, J. Ali, and M. Tanveer, "Coincidence and common fixed point theorems for nonlinear contractions in Menger PM spaces," Chaos, Solitons \& Fractals, vol. 42, no. 5, pp. 3121-3129, 2009.

[40] G. S. Jeong and B. E. Rhoades, "Some remarks for improving fixed point theorems for more than two maps," Indian Journal of Pure and Applied Mathematics, vol. 28, no. 9, pp. 1177-1196, 1997.

[41] S. M. Kang and Y. P. Kim, "Common fixed point theorems," Mathematica Japonica, vol. 37, no. 6, pp. 1031-1039, 1992.

[42] S. P. Singh and B. A. Meade, "On common fixed point theorems," Bulletin of the Australian Mathematical Society, vol. 16, no. 1, pp. 49-53, 1977. 


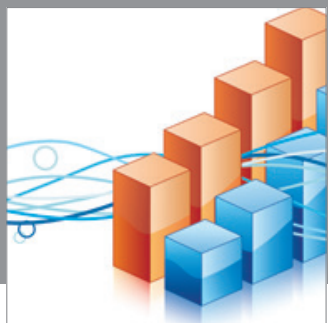

Advances in

Operations Research

mansans

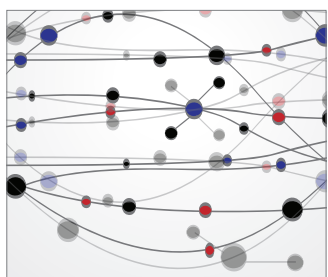

The Scientific World Journal
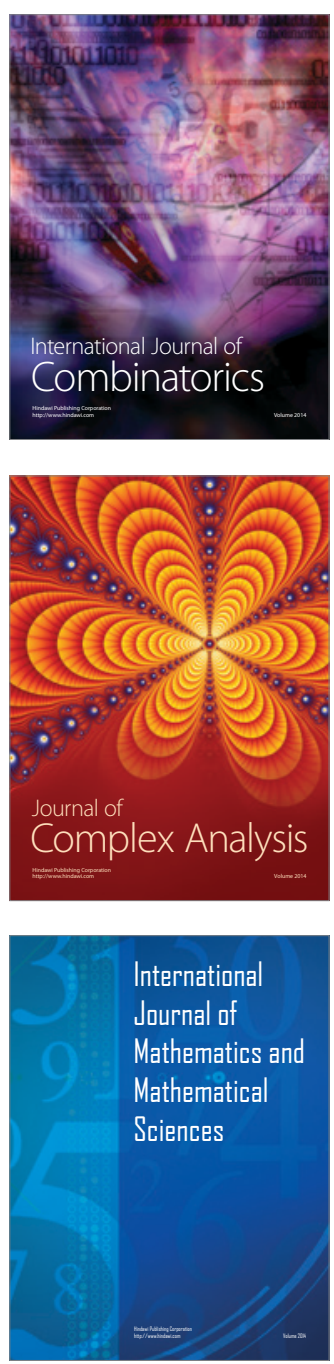
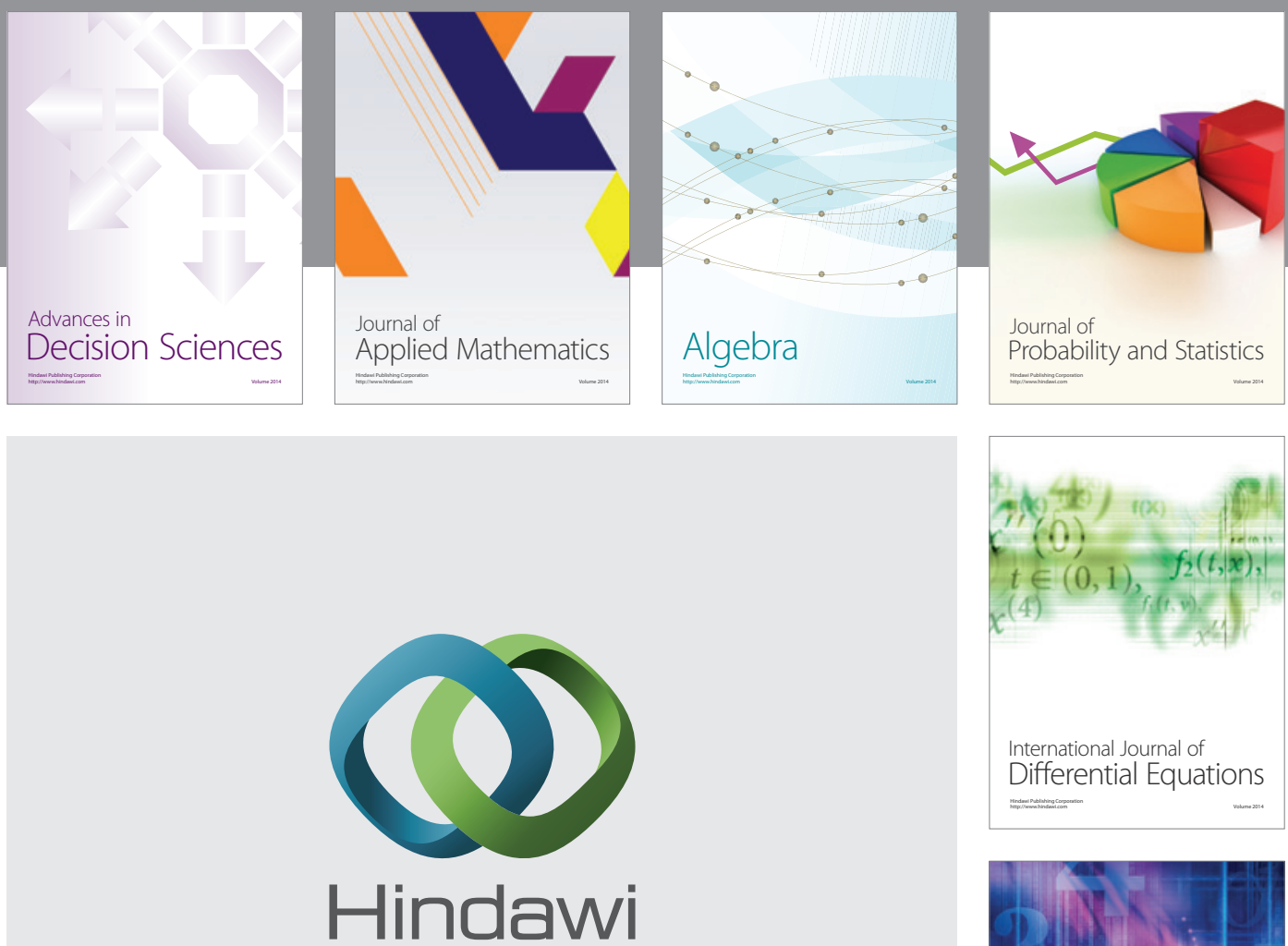

Submit your manuscripts at http://www.hindawi.com
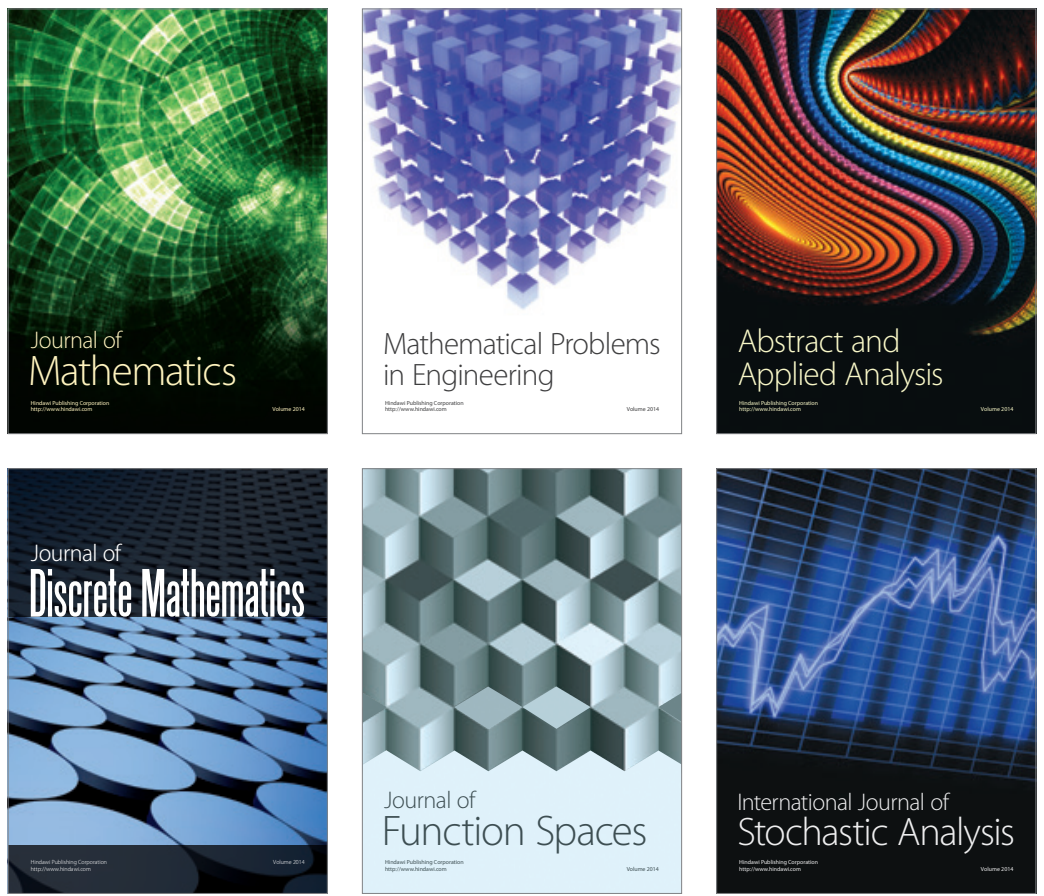

Journal of

Function Spaces

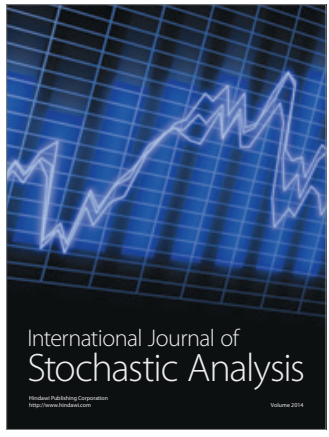

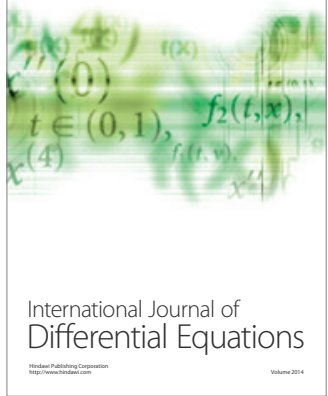
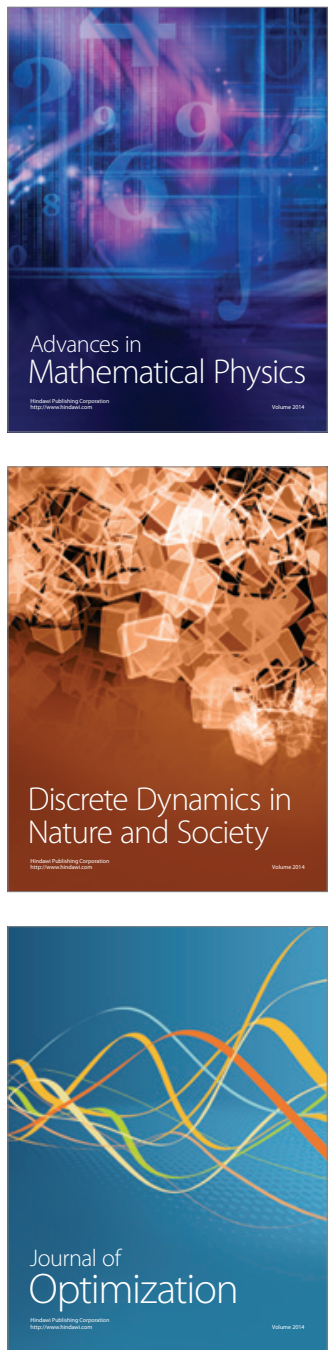